\title{
Socio-Religious Significance of Ikoro and Ekpe Festivals in Akwete Ndoki Community of Abia State, Nigeria
}

\author{
Bentina Alawari Mathias
}

\begin{abstract}
In Nigeria, cultural festivals abound to emphasize and showcase the rich cultural heritage of the people. These cultural festivals are found in all the geo-political zones of the country and they have become international events attracting tourists from all over the world. Obviously, festivals are veritable instruments for national integration and peaceful co-existence. Ikoro and Ekpe festivals are cultural festivals organized by Akwete Ndoki community to mark the end of the farming season and the beginning of a new one. This paper examines the social, political, economic and religious significance of these festivals and the effect of modernization on them. The main data collection technique used was the participant-as-observer option of participant observation. This was supplemented with the in-depth interview and Focus Group Discussion (FGD). Findings showed that Ikoro and Ekpe festivals play a vital role in the social, political, economic and religious sustenance of the community. It was also observed that Christianity has altered most of the ritual practices. Recommendations were made which includes that the date for these yearly festivals be moved from late January to any date from $24^{\text {th }}$ December to $2^{\text {nd }}$ January in order to attract more participants.
\end{abstract}

Index Terms-Ceremony, cultural heritage, festival, masquerade.

\section{INTRODUCTION}

Festival is an occasion for celebrating especially a day or time of religious or cultural significance that recurs at regular intervals. It is a time people do something they normally do not; they abstain from something they normally do; they carry to the extreme behaviours that are usually regulated by measure; they invert patterns of daily social life. Reversal, intensification, trespassing and abstinence are the four cardinal points of festival behaviour [1]. There are many festivals in Nigeria, some of which date to the period before the arrival of the major religions in this ethnically and culturally diverse society (museum collections 2013). The main Muslim and Christian festivals are often celebrated in ways that are unique to Nigeria or to the people of a particular society [2]. The Nigerian Tourism Development Corporation has been working with the state to upgrade the traditional Nigeria festival, which may become important sources of tourism revenue [3]. Among the Igbos of Nigeria, there is a wealth of cultural heritage manifested in ceremonies and festivals. Social phenomenon like marriage, birth, farming, harvest, victory and many other social institutions are celebrated. These cultural activities contain the germs of rich

Manuscript received August 1, 2013; revised October 15, 2013.

Bentina Alawari Mathias is with the Nnamdi Azikiwe University Awka Nigeria (e-mail: bentinad1@yahoo.com, mathiasbentina@gmail.com). poetry and prose, excellent music and lively drama which have not been raised far above their traditional level although present day scholars - Sociologist, Anthropologist and Literary researchers are showing sufficient interest [4]. Some of these works will be examined in relation to definition, function and structure. Ejizu noted that festivals are very popular and recurrent events in traditional African life. He summed it up by defining festivals as: Any special occasion, observance or celebration which may be religious or secular in nature and which is generally marked by merry-making, performance of music and the like [5]. Festivals, according to Onwubike can in most cases be said to be a good measure of the intensity of the religious consciousness and cultural richness of a people. He further stated that feasts are the external manifestation of religion itself in every culture and they very often include sacrifice as a prominent part of their ritual [6].

From these definitions, it is clear that festival is a celebration, a feast, a season of musical or other performance which involves joyfulness and merry making. The masquerade on the other hand plays a very significant role in the history and culture of communities in Nigeria. Though back ground origin of masquerade may differ, their overall role like traditional dances can be classified into categories. For instance, there are masquerades whose major role may be pure entertainment, ceremonial, rituals or a combination of some or all of these [7]. In short the masquerade is much more than mere entertainment. It is a vehicle for religious activities, social and political control.

Enekwe stated that the Igbo masking societies serve many other functions. According to him, they help to stabilize Igbo society and culture by presenting hereditary rights, regulating conducts and entertaining the people. It is also a training ground for both youths and adults. Above all, it provides a bond of union that transcends kinship not only within the community but also between it and others in which mask exists. He summed it up by noting that Igbo masks perform major socio-political functions in times of stress when apparently all else has failed [8]. Agogbuo stated that masquerades in Igbo culture serve various purposes in different occasions such as Christmas and Easter celebrations. They also serve useful purposes during burial ceremonies and religious functions. According to him, it is the most used entertainment media whenever a member dies [9]. Similarly Nzenwunwa noted that the masquerade performs an incredibly large number of functions and plays a vast number of roles in the life and thought of Igbo communities [10]. Enekwe and Miachi supported the above idea by stating that masquerades are used as agents of social control and as symbol of authority [11]. 
On the other hand festival period in general are times of peace. It is a time when quarrels and other differences are settled. The period of festivals as Kayode emphasized are periods when all conflicts and disputes must be abandoned for the sake of ceremonial co-operation [12]. Enekwe noted that festivals encourage friendship which is expressed in communal eating and drinking. It is a time for exchange of gifts and settlement of dispute [8]. Festivals give people the opportunity to establish extended relationship which bears with it the reciprocal bonds of social interaction [6]. According to Ejizu the rituals involved in festivals helps to rejuvenate the society as a whole. It provides occasions for peace-making, renewal of friendships and covenant relationships, get-together and merry-making. He further stated that rituals, celebrations and festivals occupy a position of signal importance in the traditional African societies [13]. Based on the fore going, the study seeks to examine the social, political, economical and religious significance of Ekpe and Ikoro in Akwete Ndoki community of Abia State in Nigeria. The study will equally examine the effect of modernization on these festivals. It is also worthy to note the Ekpe which is discussed in this paper has nothing in connection with the famous Ekpe cult of Akwa Ibom and Cross Rivers States of Nigeria. Amankulo made this clear distinction by stating that 'Ekpe' (tone marked low low) should not be confused with Ekpe (tone marked high low) the later is a secrete cult which is exclusive to men. The Ekpe cult is equally popular among the Efik and Anang of Nigeria. But Ekpe enjoys communal patronage and participation on which women and children form part of the choric force. He also stated that the Ekpe festival, an action packed festival full of songs and dances is one of such cultural event that needs a deeper investigation of which would reveal its great significance such as religious rituals, potentials, dance and drama[14].

\section{OBJECTIVES OF THE STUDY}

The following are the specific objectives of the study:

1) To identify the social significance of Ekpe and Ikoro festival in Akwete Ndoki.

2) To examine the political significance of Ekpe and Ikoro festival in Akwete Ndoki.

3) To examine the economic significance of Ekpe and Ikoro festival in Akwete Ndoki.

4) To identify the religious significance of Ekpe and Ikoro festival in Akwete Ndoki.

5) To examine the extent to which Ekpe and Ikoro festival had been affected by agents of change.

6) To suggest possible ways of improving the status and relevance of Ekpe and Ikoro festivals in Akwete Ndoki.

\section{SignifiCANCE OF THE STUDY}

Theoretically this study will provide current reference to the study of festivals. This is because in recent times scholars have not written much on festivals. It will also be relevant in the area of ethnography and cultural anthropology.

\section{THEORETICAL ORIENTATION}

The study adopts the structural functionalist perspective as its theoretical base. Functionalism arose out of the acknowledged inadequacies of the evolutionary and diffusion theories in the explanation of human societies or social life [15]. Functionalism is one of the oldest and still the dominant theoretical perspective in sociology and many other social sciences [16]. This perspective is built upon twin emphases application of the scientific method to the objective social world and use of analogy between the individual organism and society.

The emphasis on scientific method leads to the assertion that one can study the social world in the same way as one study the physical world. Thus, functionalists see the social world as "objectively real" as observable with such techniques as social surveys and interviews. Furthermore, their positivistic view of social science assumes that the study of the social world can be value free and that the investigator's values will not necessary interfere with disinterested search for social laws governing the behavour of social systems [17].

The second emphasis on the organic unity of society leads functionalist to speculate about needs which must be met for a social system to exist as well as the ways in which social institutions satisfy those needs. A functionalist might argue for instance that every society will have a religion because religious institutions have certain functions which contribute to the survival of the social system as a whole just as the organs of the body have functions which are necessary for the body's survival. Functionalism is prominent in the works of August Comte (1798 - 1857) and Herbert Spencer (1820 1903). It was later developed by Emile Durkheim (1858 1917) and refined by Tallcot Persons (1902 - 1979). Persons and the functionalist approach to sociology occupy an intermediate position between classical and contemporary sociology [18]. According to the theory, society is an organism, a system of parts all of which serve a function together for the overall effectiveness and efficiency of society.

Festivals and ceremonies are an integral part of the African traditional society. This is because man is a social being. The whole year round is full of activities ranging from festivals like Ikoro, Ekpe, Oro, Ogbogloma, Ejo to rites like birth, puberty, marriage and death. According to Onunwa in his book, The African is no mystic. "He does not spend much time on solitary contemplation of the cosmos nor does he escape from the hubris of the daily activities of life like a hermit or a monk in a cloistered cell. He is vivacious and participates actively in the daily affairs of his world in a symbolic and ritual manner" [19]. He could be said to be a "religious activist" who manifests his feelings in overt out-burst and ceremonies. His religious action is characterized not only by worship and sacrifice but also by identification and acting out. The tradition of ceremonies is deep-rooted that a failure in the role fulfillment might spell out misfortune which would not be in the interest of the society [20]. Hardly do we have any African society without a liturgical cycle because it is an indication that the society is lively. Thus, Ejizu stated that festivals are very popular and recurrent event in traditional African life. Festivals are 
cultural system which functions for societal integration and solidarity. It is times for merry-making, a time to establish new relationships, mend broken ones and maintain peace in the society. Masquerade on the other hand functions as a means of social control and entertainment. They function to satisfy the basic needs of members of the society [5].

\section{Methodology}

Akwete is a small town in Ndoki Community of Ukwa-East Local Governmnet Area of Abia State in Nigeria. It is bounded on the East by Ohanso, on the West by Asa on the North by Nkporobu and the South by part of Imo River the Ndoki waterside popularly known as Ndoki harbour. Akwete people came from Umuosi another Ndoki Community in Rivers State of Nigeria. History has it that the son of Ihueze in Umuosi saw a mass of Land across the Ndoki River when he was tapping palm wine. Thus, he took permission from his father and moved to their present settlement with his family. They were the first settlers of Akwete. That is why there is Umuihueze I in Umuosi and Umuihueze II in Akwete.

Their system of Government is monarchy. Their men engage in trading, fishing and farming while most of the women weave the famous Akwete cloth [21]. Akwete has a population of 7,080 [22]. The scope of this study is limited to Ikoro and Ekpe festivals in Akwete Ndoki community. It is true that Akwete people have other festivals like $O w u$, Okonko, Ejo, Abigolo and Ubagala, but these shall not be our immediate concern.

\section{SAMPLing TeChNiQUE}

Sampling is due and careful selection of a part to represent a whole. It is necessary in research activities because it is usually impossible to cover the entire population of study. However, in research of this kind, the issue of sampling is not applicable. Ethnographers do not systematically manipulate their subjects. Rather, they work in the actual community and form personal relationships with local people as they study their lives [23].

\section{METHOD OF DATA COLLECTION}

The method for collecting data for this study is oral interview.

The researcher with the help of two research assistance conducted in-depth interview with the following categories of people:

1) Business men

2) Business women

3) Akwete weaving cooperation members

4) Fishermen and farmers (men and women)

5) Students

The researcher also used participant observation as the main instrument for data collection. The method of data analysis for this type of inquiry is always narrative and descriptive [24]. Thus, the researcher adopted narrative and descriptive method of data analysis.

\section{FINDINGS}

The Ekpe festival, an action packed festival, full of songs and dance is a cultural event. It is a social and religious institution among the Ndoki people operating on an age grade system. Each new age grade institutes its own masquerade. Thus, some masquerades have become extinct as a result of the passing away of the age-grade that owned them. Ekpe and Ikoro originated in Ndoki land though no written record had been found concerning the actual date of their introduction. However the advent of Christianity with its acceptance among the Ndoki's had modified the basic elements of the festivals. It is this modified version which now became a tourist attraction. These dances also known as Egwu Ike or Egwu Umuokorobia is organized on age grade basis. Each age grade has its own dancers and masquerades. The names of these masquerades depict particular observations or events in the community. Some of the names include Osobo, Nwankwo, ete, Nwichi, Ada-baba, Akpu, Garagadanga, Ebule, Nwanyi-Lagos and many others. As the masquerades dance, the men do there dance known as Egwu Ike while the women organize the nyenye dance and follow behind the Ekpe festival commences on eke market day which is a 'Holy' day in Akwete and last for days. The scene is illustrated in Fig. 1.

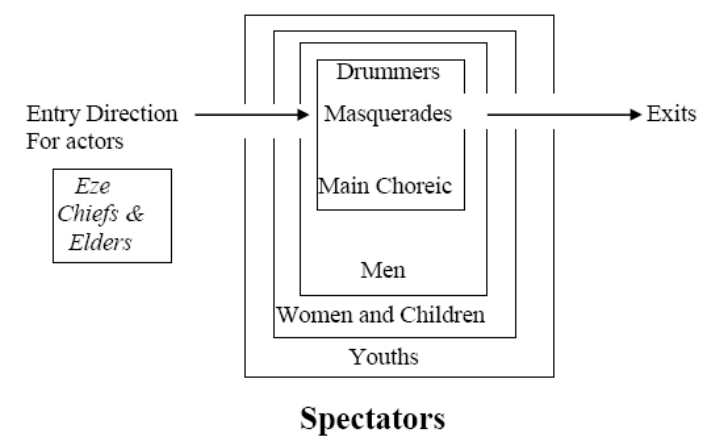

Fig. 1. The arena stage of Ekpe festival.

Ikoro also known as egwu ndi Eze and egwu nganga is a traditional dance organized in honour of hero's of the land. Like Chief Nwankwo George who redeemed the village with a huge amount of money from neighbouring villages who threatened to take them away as slaves because they were indebted to them. Ikoro dance is owned by the Eze, Chiefs and elders of the community. They announce the date for the dance through a town crier who goes round the town at night to notify the people of the date for the commencement of the dance. Ikoro dance starts on Eke market day as well and lasts for four days.

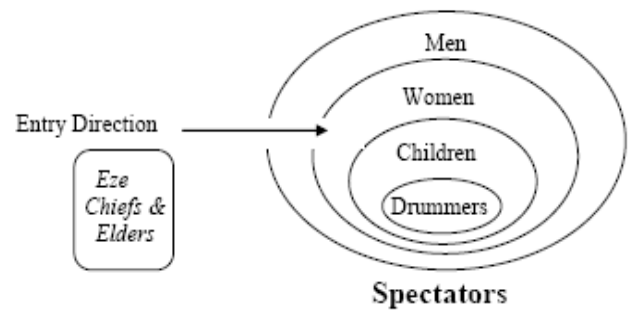

Fig. 2. The Arena Stage for Ikoro.

The Ikoro dance comes after the Ekpe festival. It is a 
period of merry-making after which the Eze prays for the community, the new planting season and journey mercies for the sons and daughters who came home for the celebration. The arena is illustrated in Fig. 2.

\section{A. Significance of Ekpe and Ikoro Festivals}

Festivals have social, political, economic as well as religious significance in African societies. A significant social function of festivals is recreation. It is also during festivals that lineage members, their consanguine and affinal kins as well as friends come together to eat drink and be merry. It is also a time of reunion between the living and the death [25].

\section{B. Social Significance of Ekpe and Ikoro Festival}

The social role of Ekpe and Ikoro should not be over emphasized. The richness, colour and diversity of various dancers in Ikoro make a splendid picture. The festival period is a period of fancy dress parade. Akwete sons and daughters and strangers come home. Young men use the opportunity to see the young ladies they marry. Also visitors to the village see wives and husbands to marry. It is a time to establish lasting relationships. The nyenye songs by the women during the Ikoro festival are usually composed on the spot by inspired members. They are simple and easy to learn and serve as a check for social and moral conduct. Any miss-deed in the society is translated into an Ikoro chant and this serves as a deterrent to further perpetrators. Also society enforces good behavior by publicly denouncing evil deeds during Ikoro festival. During the festival, the young and old sing round the town pestering those who have misbehaved in one way or the other during the year. Such songs bring the culprits to the lime light and their families also feel the impact. Ikoro has also made Akwete town famous in the country. The Ikoro music forms the background signal to 7:00pm network news of Radio Nigeria I News Panorama.

\section{Political Significance of Ekpe and Ikoro Festival}

The festival period creates a forum for community meetings concerning the welfare and development of the community. Ekpe masquerade is regarded as messenger of peace, order, tranquility and solidarity. They help to keep public morality by fearlessly announcing and admonishing evil dowers in the society. Ekpe performs judicial functions; it acts as law enforcement agent in the collection of fines and penalties from people who violated the norms and values of the land. It acted as judge and also went unbehalf of the people to court prior to colonization.

Not only that, government ministers also take advantage of the festival which has brought a lot of people (Citizens) together to announce development projects, government policies to the people and to educate them on important issues affecting the locality, town or an area. Political parties also use the opportunity to create awareness in the society.

\section{Economical Significance of Ekpe and Ikoro Festival}

Carving of the Isiekpe and weaving of Obu (Mask) of the Ekpe masquerade provide reasonable employment for artists. Not only that, gifts of money and other valuable things are given to the masquerades and dancers during performance.
The money is either shared among members or put into community development projects. Visitors who also come to witness the festival contribute economically to the locality.

\section{E. Religious Significance of Ekpe and Ikoro Festival}

God and the divine beings are not mere intellectual fabrications of the African mind. They are real to him and he can personify them. That is why it is difficult to get an atheist or agnostic among traditional Africans. In short there is no religious vacuum in the traditional African life [19]. Ekpe and Ikoro festivals that mark the end of a planting season and the beginning of a new one are one of such religious activity. It is a time when the Eze, Chiefs and elders pour libation and pray to the God almighty (Chineke Akwete) to keep and protect his people. It is also a time to thank him for the previous year and ask for mercy for the coming planting season. The song or nyenye that they sing on the last day of the festival are praise songs thanking God for seeing them through the festival and asking him to be with the people through-out the next year.

\section{F. Effect of Change on the Festival}

Several aspects of Ekpe and Ikoro have been affected by change. Change is a necessary phenomenon in the existence of living things. Societies and religions have characteristic of living things hence they are prone to change [26].The agents of change include:

\section{G. Christianity}

The advent of Christianity to Akwete in 1886 affected most cultural practices in the town [21]. The major aspect that was affected by this agent of change is the rituals involved in the preparation stage. Almost all the rituals that were performed before the festivals commence was affected. Before the advent of Christianity, the masquerades are secluded for two days where they are fed with Agbugba (Local fat) and Gin, Cock was used to perform ritual and then tied to the masquerade as it is performing, some masquerade has human heads as their mask. All these are no longer seen as part of the celebration.

For the Ikoro festival, the only costume was the famous Akwete cloth that is tied by both male and female. Now we see young men wear trousers while their females counter-part wear gowns or at times trousers to the festival. As a result of this agent of change, the number of participants in the festival has reduced. Some adherents of Christianity do not participate. Most young men especially members of Christian group do not also join in clearing the village square neither do most women participate in fetching water both to pour on the ground to prevent dust and to pour inside the Ikoro drums. The people no longer fear and reverence the masquerades.

\section{H. Western Education}

The arrival of the Colonialist not only destroyed the Nwiyieke shrine but also saw the young men who form the bulk of the Ekpe and Ikoro dancers leave the countryside to the cities as students and in search for employment. The educated members of the community saw the festivals as primitive and as event that is meant for elders and the uneducated. 


\section{Cultural Contact}

Our informants had it that the contact which Akwete people had with Abiriba and Anang people resulted in some of the Ekpe masquerades carrying fire on their heads. For instance the Nwadibia masquerade carries fire while Gragadanga and Ete carry hot charcoal that smokes heavily. These were not originally features of Ekpe festival. It should also be noted that the coming of the European Colonialists inflicted a deep cut in the culture of Akwete people. In Achebe's words he has put a knife on the things that held us, (Akwete) together and we have fallen apart [27]. Their contact with Akwete culture has led to a shift from the original way of observing these festivals. According to Ude, as a result of our encounter with Colonialism and all its influences, the onetime confident and proud African emerged a mere marionette in the hands of the new masters. Brainwashed and gulled into accepting his inferior position, he hated everything African including his skin. He throw all his Africaness, manhood, religion etc into the bin and like a baby, he started from the scratch to learn the ways of his master [28].

These agents of change have damaged the psyche of Akwete people, thereby reducing the once revered Ekpe masquerade and Ikoro dance into a mere social gathering where no taboo is observed. Unlike before, anybody can now wear whatever he/she likes to Ikoro dance. Women now touch the Ekpe masquerade a thing forbidden in the past.

\section{CONCLUSION AND RECOMMENDATIONS}

Ekpe and Ikoro festivals come up during the resting period after harvest and next planting season. These festivals afford the people opportunity to relax and have fun. Despite the impact made by Christianity, Western education, urbanization and technology one would have expected a sharp decline of interest in these traditional institutions. It is particularly surprising that with the rapid expansion of Christianity in Akwete. Ekpe and Ikoro festivals still enjoy good patronage even from educated men and women who profess the Christian faith. The obvious question is what draws people to these festivals? It should be noted that culture moulds the interest tastes and values of the individual [29]. In the event of strains and stress of urban life with the resulting socio-economic problems, the individual goes home to seek solace in the traditional way. These festivals are constructive rather than destructive to members of the society. Prior to Colonialisation, Ekpe was the major agent of social control. It acted as judge and also goes on behalf of the people to the court. The Nyenye songs during the Ikoro act as a corrective measure to criminal acts.

Furthermore, they act as entertainment to the people. It is then essential that these invaluable institutions be preserved. There are also the negative aspects of Ekpe festival. For instance the used and abuse of alcohol. This is because young men drink a lot of alcohol - local gin which they believe makes them bold and active. This has resulted in many of the fighting and inflicting of wounds witnessed on any little misunderstanding that would have been ignore under normal situation. Not only that the rate of destruction of properties on the last day of the festival is high. The last day of the Ikoro dance lasts longer than other days. Very often it ends around 1:00am, thus the youth use that opportunity to engage in immoral activities. A lot of teenage girls who engage in unprotected sexual activities may contact sexually transmitted deceases or become pregnant and eventually drop out of schools.

In as much as we admit that these festivals encourage moral laxity among the youths. There is yet the positive aspect of these festivals and efforts should be made by the chiefs, Elders and the Community in general to foster these aspects of the festivals that are of social, political, economic and religious importance to the society.

Based on the foregoing, the study makes the following recommendations.

1) All harmful groups, those groups that use knives, gun and even magical charms like the Ejeselem group should be banned from attending the festivals. This is because; these groups at times go violent and destroy lives and properties.

2) All rituals and sacrifice involved in the preparation stage of the festival should be removed. This will encourage more participation by members of the community. Most Christian organizations discourage their members from attending these festivals because of the rituals involved.

3) The original costume of the Ikoro festival should be reactivated. The tying of Akwete cloth and wearing of Ajara a type of beads at the ankle and wrists should be encouraged. This gives the festival a characteristic rhythm.

4) The time for observing these festivals should be changed to any date from the $24^{\text {th }}$ of December to the beginning of January. This is because with Westernization and urbanization most people have left farming and fishing for white color jobs in the cities. They only come home for Christmas and New Year celebration. Thus, by the early days of January, they are forced to go back to the city to resume work. If the time is changed, it will give more people the opportunity to participate in the greatly cherished festivals of Ekpe and Ikoro Akwete.

\section{REFERENCE}

[1] B. Babcock, The Reversible World: Symbolic Inversion in Art and Society, Ithaca: Cornell University Press, 1978.

[2] L. J. Alade, "Nigerian festival and Cultural Tours," in African Travel Magazine, vol. 1, no. 2, pp. 1, 2013.

[3] Nigeria Festivals in Nigeria. [Online]. Available: http://www.onlinenigeria.com/festivals/.

[4] T. Onyefulu, An African Christma, Francis Lincolun Ltd P7, 2007.

[5] C. I. Ejizu, The Meaning and Significance of Festivals in Traditional African Life, by E. Ekpunobi and I. Ezeaku, Ed. Enugu: New Age Publisher, 1990, pp. 134.

[6] O. A. Onwubiko, Wisdom Lecture on African Thought and Culture, Owerri: Totan Publishers Ltd, 2008, pp. 65.

[7] S. A. Imobighe, Masquerade in Nigerian Culture, Owerri: Totan publishers, 2003, ch. 2

[8] O. O. Enekwe, Igbo Mask: The Oneness of Ritual and Theater, Ile Ife: University of Ife press Nigeria, 1987.

[9] D. M. Agogbuo, "Mask and masquerade in Igbo culture with particular reference to Imo state," in The Masquereade in Nigeria History and Culture, Nzewunwa UNIPORT Press, January, 1983.

[10] N. Nzenwa, The Masquerade in Nigeria History and Culture. Port-Harcourt Uniport Press, 1983. 
[11] O. O. Enekwe and T. A. Miachi, "Masquerades as agents of social control among Igala," in a Nigerian Magazine publication Department of Information and culture Lagos, vol. 1, no. 1, pp. 4, April 2007.

[12] J. O. Kayode, Understanding African Traditional Religion, Ile Ife: University of Ife press Nigeria 1984.

[13] C. I. Ejizu, "The role of Rituals in the renaissance of African culture," in The Bulletin of African Religion and Culture, National Association for African Traditional Religion, vol. 1, no. 1, April 1987.

[14] J. N. Amankulo, "Ekpe festival as religious ritual and dance drama," Ikenga Journal of African Studies, University of Nigeria Nsukka, vol. 1 no. 2, July 1972.

[15] P. J. Ezeh, A survey of socio-anthropological thought for African Students, Enugu: Lifegate publisher, 2012, ch. 1.

[16] O. A. Ogunbameru, Sociological Theory, Ibadan: PentHouse Publications Nigeria, 2008, ch. 1.

[17] B. A. Ritzer, Structure and Function in Primitive Society, London: Chen and West Ltd., 1996.

[18] M. Haralambus and M. Holborn, Sociology: Themes and Perspectives, London: Harper Collins Publisher Limited, 2006, ch. 11.

[19] U. Onunwa, "Aesthetics in the service of spiritual: An analysis of an African Example," in Socio-Philophical perspective of African Traditional Religion, E. Ekpunobi and I. Ezeaku, Ed. Enugu: New Age Publishers, 1990, pp. 7-10.

[20] V. C. Uchendu, The Igbo South East Nigeria, USA, Holt Rinehart and Wiston, 1965.

[21] M. N. George, Akwete at a Glance, Aba: Apex paper mill, 1982.

[22] National Population Census Nigerian Census Figure, 2006.

[23] E. Babbie, History and Theory in Anthropology, Cambridge CUP 2005, ch. 4.

[24] P. Okpoko and P. J. Ezeh, Methods in Quantitative Research, Nsukka: Great AP Express Publishers Limited 2011
[25] T. A. Michi, "Masquerade in Igbo traditional," The masquerade in Nigeria History and Culture, Nzenwunwa Uniport Press January, 1983, pp. 87-93.

[26] J. S. Mbiti, African Religion and Philosophy, London: Heinemann, 1980, pp. 216.

[27] C. Achebe, Things Fall Apart, Classics ed. England: Heinemann, 2008 pp. 141.

[28] K. A. Ude, "Manhood and Religious: A study of initial rites in some Igbo speaking chain in Nigeria," pp. 75, 1987.

[29] O. U. Kalu, "Readings in African humanities," African Cultural Development, University of Nigeria Nsukka (UNN): Fourth Dimension, 1980, pp. 27.

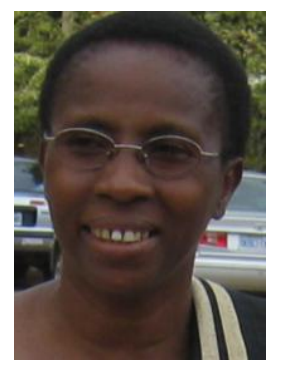

Bentina Alawari Mathias is a senior lecturer at the Department of Sociology/Anthropology, Nnamdi Azikiwe University Awka. She was born at B'dere, a small town in south-south Nigeria. She is a member of Nigerian Anthropological/Sociological Association (NASA), American Sociological Association (ASA) and International Sociological Association (ISA).She was educated at University of Port Harcourt Nigeria where she obtained BA (1991), MSc (1997) and Ph. D (2004) degrees in Sociology. Her area of specialization is Institutional Analysis and her research focus includes: Gender studies, Conflict and Security studies, Medical Sociology and International relations. She has published in scholarly journal both national and international. 